\title{
PENGARUH METODE PLYOMETRIC TERHADAP KEMAMPUAN VERTICAL JUMP PADA SISWA EKSTRAKURIKULER BOLA VOLI DI SMKN 1 KAYONG UTARA
}

\author{
Pardik, Eka Supriatna, Fitriana Puspa Hidasari. \\ Program Studi Pendidikan Jasmani FKIP Untan Pontianak \\ Email:f1101151002@student.untan.ac.id
}

\begin{abstract}
Pardik (2021) The Effect of Plyometric Methods on Vertical Jump Women in Volleyball Extracurricular Students at SMKN 1 Kayong Utara (Supervisor I: Eka Supriatna M.Pd and Advisor II: Fitriana Puspa Hidasari M.Or). The problem in this study is the vertical jump ability of volleyball players at SMKN 1 Kayong Utara, who take volleyball extracurricular activities is still categorized as lacking and the plyometrix method has not been applied. The purpose of this study was "is there an effect of the plyometrix method on the vertcal jump ability of volleyball extracurricular students at SMKN 1 Kayong Utara. The purpose of this research is to increase the vertical jump ability. The population in this study were 20 students who took extracurricular activities at SMKN 1 Kayong Utara. Sampling in this study using a saturated sampling technique, namely the technique of determining the sample when all populations are used as samples. The form of research used in this research is Pre Experimental Design with the One-Group Pretest-Posttest Desingn model, which is a research design that is given a pretest before being given treatment, so the results of the treatment can be known to be more accurate. Based on the calculated chi square for pretest $=4.958$ and posttest $=7.62$ smaller than the chi squared table (9.488), the distribution of the 20 athletes' statistical data can be declared normal, F count is smaller than F table $2.28<4.38$ for $F$ table $5 \%$, it can be concluded that the variant of the data to be analyzed is homogeneous. The calculation of the T test obtained the value of $t$ count $=6.955>t$ table $=2.093$. The percentage increase in vertical jump exercise using the plyometrix method is $19.5 \%$. Thus, the vertical jump exercise using the plyometrix method is proven to have an effect on the jump height of students who take the Volleyball Extracurricular at SMKN 1 Kayong Utara.
\end{abstract}

Keywords: plyometric, vertical jump

\section{PENDAHULUAN}

Ekstrakurikuler adalah kegiatan pendidikan yang dilakukan peserta didik di luar jam belajar kurikulum standar. Kegiatan ekstrakurikuler ditujukan agar peserta didik dapat mengembangkan kepribadian, minat, dan kemampuannya di berbagai bidang di luar bidang akademik (Damanik,2014:19).

Manfaat ekstrakurikuler dibidang akademik yaitu berupa kegiatan pengembangan kemampuan potensi dan bakat siswa di bidang akedemik yang memiliki manfaat yaitu untuk mengasah kemampuan berpikir kritis, meningkatkan pengetahuan, dan memiliki banyak wawasan; manfaat ekstrakurikuler dibidang non akademik yang berupa aktivitas fisik yaitu keterampilan jasmani, merupakan suatu kegiatan yang dapat membina seseorang untuk dapat menjadi sehat atau menjadikan lebih baik dari sebelumnya (Nafi'ah, 2014: 803).

Menurut Zubaedi (2013: 316) beberapa fungsi ekstrakurikuler sebagai berikut: Pengembangan, yaitu fungsi kegiatan ekstrakurikuler untuk mengembangan kemampuan dan kreativitas peserta didik sesuai dengan potensi, bakat, dan minat mereka. Social, yaitu fungsi kegiata ekstrakurikuler untuk mengembangkan kemampuan dan rasa 
tanggung jawab social peserta didik. Rekreatif, fungsi kegiatan ekstrakurikuler untuk mengembangkan suasana rileks, mengembirakan dan menyenangkan bagi peserta didik yang menunjang proses perkembangan. Persiapan karir, yaitu fungsi kegiatan ekstrakurikuler untuk mengembangkan kesiapan karir peserta didik. Agar pembinaan memperoleh hasil yang maksimal diperlukan latihan tambahan seperti latihan

Berdasarkan hasil observasi yang dilakukan pada kegiatan ektrakulikuler di SMKN 1 Kayong Utara terdapat masalah yaitu kurangnya tinggi badan dan lemahnya power lompatan. Hal ini diakibatkan karena kurangnya latihan fisik. Pernyataan ini diperoleh dari hasil wawancara terhadap pelatih yang membina ekstrakurikuler di sekolah tersebut. Selain dari hasil wawancara peneliti juga telah melakukan test awal yang menggunakan test vertical jump dengan papan ukur. Selain tinggi lompatan tinggi badan peserta ekstrakulikuler juga tidak mencapai standar yang ditetapkan. Sejalan dengan Setyawan (2015) yang menyatakan bahwa tinggi badan mempengaruhi tinggi lompatan.

Untuk mengatasi kekurangan tinggi badan dan tinggi lompatan peserta ekstrakurikuler di SMKN 1 Kayong Utara alternatif yang dapat dilakukan yaitu dengan meningkatkan kemampuan vertical jump. Salah satu metode yang dapat meningkatkan kemampuan vertical jump adalah latihan plyometric. Terdapat beberapa jenis latihan plyometric salah satunya yaitu plyometric box. Metode latihan ini memiliki kelebihan yaitu dapat meningkatkan tenaga ledak otot yang pada akhirnya akan mempengaruhi hasil vertical jump (Pertiwi, 2016: 4). "Semakin besar daya ledak otot maka kemampuan vertical jumpnya juga akan semakin tinggi”. hal ini dibuktikan pada penelitian yang dilakukan oleh Baskara (2019) "yang menyatakan bahwa penggunaan metode latihan plyometric box dapat meningkatkan vertical jump sebesar 4, 44\%".
Peserta ekstrakurikuler akan mudah melakukan vertical jump apabila memiliki tinggi lompatan yang maksimal dan daya ledak otot tungkai yang baik, dengan di terapkannya bentuk latihan plyometric box ini diharapkan peserta akan lebih baik lagi pada saat melakukan vertical jump. Oleh karena itu peneliti ingin melakukan sebuah penelitian eksperimen dengan judul "Pengaruh Terhadap Kemampuan vertical jump Pada Siswa Ekstrakurikuler Bola Voli SMKN 1 Kayong Utara".

Menurut Listina (2012: 2) "bola voli adalah permainan beregu yang dalam satu regu antar pemain satu sama lain harus saling mendukung dan bahu-membahu membentuk regu yang kompak".

Pelatih adalah orang yang menguasai secara mendalam baik teori maupun praktik, kondisi yang terjadi di lapangan, serta strategi-strategi yang tepat untuk menghadapinya. Pelatih yang baik adalah orang yang imajinatif dalam melasanakan program olahraga dengan berlansan pada ilmu (Dwiyogo, 2009:138).

Cabang olahraga untuk mendapatkan hasil yang maksimal tidak lepas dari peranan seorang pelatih, dimana tugas dari seorang pelatih tidak hanya membina atau melatih pemain dalam berlatih akan tetapi lebih dari itu seorang pelatih harus bisa mengetahui karrakteristik atau kejiwaan seorang atlet yang dihadapinya.

Kegiatan ilimiah yang dilakukan seorang maupun sekelompok dalam penyelidikan, pengamatan, analisis serta memecahan masalah untuk menemkan suatu hal baru (Indri dan Juliaster, 2019:11). Pelatih maupun atlet dituntut memiliki kemamapuan untuk mengetahui hasil-hasil riset dalam proses melati yang dapat ditemukan pada buku-buku, jurnal maupun internet. Dengan mengetahui hasilhasil riset diharapkan pelatih maupun atlet dapat menambah pengetahuan dan wawasan terhadap olahraga yang digeluti.

Menurut Suharno (dalam Putra, 2015: 8) "bahwa penguasaan teknik dasar permaianan bola voli harus benar-benar 
dilakukan, sebab penguasaan teknik dasar bola voli merupakan salah satu unsur yang turut menentukan menang kalahnya suatu regu dalam pertandingan, disampig kondisi fisik, taktik dan mental.

Plyometric adalah "latihan atau ulangan yang bertujuan menghubungkan gerakan kecepatan untuk menghasilkan gerakan-gerakan eksplosif" (Lubis, 2009). Menurut Ward dan Tallesz latihan plyometric mempergunakan tenaga gravitasi untuk menyimpan energy dalam otot dan dengan segera melepaskan energi yang berlawanan.

Latihan plyometric adalah salah satu latihan yang favorit yang dilakukan oleh pelatih saat ini, terutama kepada cabang olahraga yang membutuhkan kemampuan power otot tungkai atau otot lengan. Sebagian dapat dilakukan lebih terampil jika atlet memiliki power yang merupakan gabungan dari kekuatan dan kecepatan. Gerakan-gerakan plyometric sering dilakukan dalam cabang olahraga yang menggunakan power. Pada olahraga bola voli power tungkai adalah salah satu faktor terpenting untuk meraih prestasi.

Latihan Plyometric dapat merangsang berbagai macam perubahan dalam sistem syaraf otot, meningkatkan stabilitas kelompok-kelompok otot untuk merespon lebih cepat dan bertenaga dalam perubahanperubahan singkat dan cepat pada panjang otot, hal yang penting dalam latihan plyometric umumnya adalah keadaan sistem syaraf otot untuk melakukan perubahan arah yang lebih cepat dan bertenaga (Arizal, 2019:1129).

\section{METODE PENELITIAN}

Pada penelitian ini peneliti menggunakan metode penelitian kuantitatif, tepatnya peneliti melakukan jenis penelitian pree experimental Design. Menurut Prasetyo dan Jannah (2012:161) "Jenis penelitian eksperimen ini digunakan karena keterbatasan jumlah subjek yang akan diteliti."

Berdasarkan uraian di atas, maka bentuk penelitian ekperimen yang digunakan oleh penulis adalah bentuk onegrup pre-test-post-test design. Pada desain ini terdapat pre-test, sebelum diberi perlakuan. Dengan demikian hasil perlakuan dapat diketahui lebih akurat, karena dapat membandingkan dengan keadaan sebelum diberi perlakuan.

populasi dari penelitian ini adalah anggota pembinaan ekstrakulikuler cabor bola voli di SMKN 1 Kayong Utara. Ekstrakurikuler cabor bola voli di sekolah tersebuh beranggotakan 20 atlit yang terdiri dari siswa putra kelas X dan kelas XI.

Karena jumlah populasi yang tidak sampai 30 orang maka untuk menentukan sampelnya peneliti menggunakan teknik sampling jenuh dimana menurut Sugiyono (2017:85) "sampling jenuh adalah teknik penentuan sample bila semua anggota populasi digunakan sebagai sample”. Hal ini sering dilakukan bila jumlah populasi relatif kecil, kurang dari 30 orang, atau penelitian yang ingin membuat generalisasi dengan kesalahan yang sangat kecil.

Berdasarkan pernyataan di atas disimpulkan bahwa sampel yang diambil adalah keseluruhan dari populasi, yaitu anggota Ekstrakurikuler Bola Voli SMKN 1 Kayong Utara yang berjumlah 20 orang.

Untuk memperoleh data yang di kehendaki dan sesuai dalam penelitian ini, peneliti menggunakan metode penghitungan di papan ukur vertical jump yang nantinya akan digunakan dalam pengambilan data pada pre-test dan posttest (setelah diberikan perlakuan kepada sampel).

Dalam penelitian kuantitatif, analisis data merupakan kegiatan setelah data dari seluruh responden atau sumber data lain terkumpul. Kegiatan dalam analisis data adalah: mengelompokan data berdasarkan variabel dan jenis responden, mentabulasi data berdasarkan variabel dari seluruh responden, menyajikan data tiap variabel yang diteliti, melakukan perhitungan untuk menjawab rumusan masalah, dan melakukan perhitungan untuk menguji hipotesis yang telah diajukan (Sugiyono, 2009:147). 


\section{HASIL PENELITIAN DAN \\ PEMBAHASAN}

\section{Hasil Penelitian}

Penelitian ini dilaksanakan di SMK Negeri 1 Kayong Utara. Dalam penelitian ini yang dijadikan sampel adalah peserta didik Ekstrakurikuler bola voli SMK Negeri 1 Kayong utara yang berjumlah 20 orang. Adapun tujuan dari penelitian ini adalah untuk meningkatkan kemampuan vertical jump peserta ekstrakurikuler bola voli SMK Negeri 1 Kayong utara melalui metode plyometric.

Hasil penelitian ini meliputi deskripsi uji normalitas, uji homog enitas, uji pengaruh (uji t), dan persentase peningkatan. Deskripsi data penelitian berfungsi untuk mempermudakan pembacaan data penelitian. Dalam bab ini akan disajikan data penelitian, dari pretest dan posttest hasil tes vertical jump peserta ekstrakurikuler SMK Negeri 1 Kayong
Utara. Deskripsi data pretest didasarkan pada data yang diperoleh dari hasil tes pengukuran pada saat pretest atau sebelum diberikan perlakuan menggunakan metode plyometric. Berdasarkan hasil analisis deskriptif data prestest hasil tes vertical jump pada peserta ekstrakurikuler SMK Negeri 1 Kayong Utara, diketahui bahwah nilai rata-rata prestest hasil tes vertical jump belajar peserta ekstrakurikuler SMK Negeri 1 Kayong Utara sebesar 48,6. Hasil pretest tertinggi yang dicapai peserta adalah 71 dan terendah adalah 41. Sedangkan standar deviasi atau penyimpangan dari nilai rata-rata pretest adalah 7,36. Jumlah peserta ekstrakurikuler yang mengikuti pretest sebanyak 20 orang.

Tabel 4.1 Deskripsi Data Pretest Hasil tes vertical jump

\begin{tabular}{|l|c|c|c|c|c|c|}
\hline \multirow{2}{*}{$\begin{array}{l}\text { Kemampuan } \\
\text { vertical jump }\end{array}$} & & Peserta & \multicolumn{2}{|c|}{ Nilai } & Nilai \\
Ekscul & & & Terendah & Tertinggi & $\begin{array}{c}\text { Standar } \\
\text { Reviasi } \\
\text { rata }\end{array}$ & \\
\cline { 3 - 6 } & & 20 & 41 & 71 & 48,6 & 7,36 \\
\hline
\end{tabular}

Data pretest hasil tes vertical jump peserta ekstrakurikuler SMK Negeri 1 Kayong Utara dapat pula di sajikan dalam bentuk penghitungan frekuensi dan persentase kumulatif dapat dicari dengan cara jumlah frekuensi kelas di bawahnya ditambah jumlah frekuensi kelas yang bersangkutan. Sedangkan persentase kumulatif dihitung dengan cara jumlah frekuensi kumulatif kelas yang bersangkutan dibagi jumlah subjek dan kemudian dikalikan 100. Berikut tabel distribusi frekuensi dan persentase kumulatif data pretest hasil tes vertical jump apabila digambarkan dalam bentuk grafik, maka berikut adalah grafik data pretest hasil tes vertical jump peserta ekstrakurikuler SMK Negeri 1 kayong Utara. 
Grafik Data Pretest Hasil vertical jump

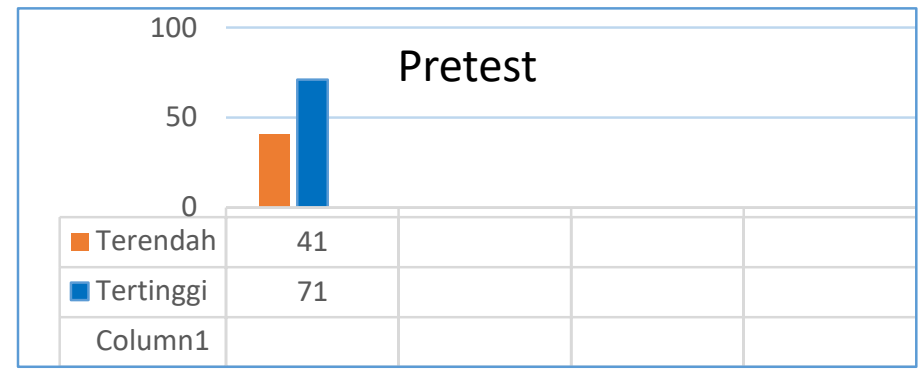

Deskrisi data posttest didasarkan deskriptif data posttest hasil tes vertical jump pada peserta ekstrakurikuler SMK pada data yang diperoleh dari hasil tes pengukuran pada saat posttets atau setelah diberikan perlakuan Negeri 1 Kayong Utara dapat dilihat menggunakan metode plyometric. Hasil analisis

deskriptif data posttest Hasil tes vertical jump

\begin{tabular}{|c|c|c|c|c|c|}
\hline \multirow{3}{*}{$\begin{array}{l}\text { Kemampuan } \\
\text { vertical jump }\end{array}$} & \multirow{2}{*}{$\begin{array}{l}\text { Peserta } \\
\text { Ekscul }\end{array}$} & \multicolumn{2}{|c|}{ Nilai } & \multirow{2}{*}{$\begin{array}{c}\text { Nilai } \\
\text { Rata- } \\
\text { rata }\end{array}$} & \multirow{2}{*}{$\begin{array}{l}\text { Standar } \\
\text { Deviasi }\end{array}$} \\
\hline & & Terendah & Tertinggi & & \\
\hline & 20 & 44 & 73 & 58,1 & 6,73 \\
\hline
\end{tabular}

diketahui bahwah nilai rata-rata posttest hasil tes vertical jump pada peserta ekstrakurikuler SMK Negeri 1 Kayong Utara sebesar 58,1. Hasil posttest tertinggi yang dicapai peserta ekstrakurikuler adalah 73 dan terendah adalah 44. Sedangkan standar deviasi atau penyimpangan dari nilai rata-rata posttest adalah 6,73. Jumlah peserta yang mengikuti posttest sebanyak 20 orang.

Data posttest hasil tes vertical jump peserta ekstrakurikuler SMK Negeri 1 Kayong Utara dapat pula di sajikan dalam bentuk penghitungan frekuensi dan persentase kumulatif dapat dicari dengan cara jumlah frekuensi kelas di bawahnya ditambah jumlah frekuensi kelas yang bersangkutan. Sedangkan persentase kumulatif dihitung dengan cara jumlah frekuensi kumulatif kelas yang bersangkutan dibagi jumlah subjek dan kemudian dikalikan 100. Berikut tabel distribusi frekuensi hasil tes vertical jump digambarkan dalam bentuk grafik, maka berikut adalah grafik data posttest hasil tes vertical jump : 


\section{Grafik Data Posttest Hasil tes vertical jump}

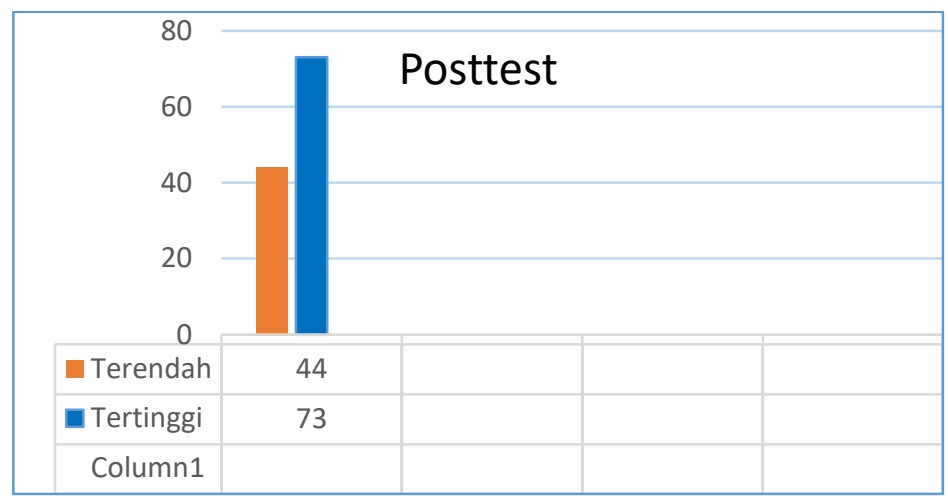

Uji normalitas dilakukan untuk mengetahui apakah data pretest dan posttest hasil tes vertical jump peserta ekstrakurikuler yang diteliti berdistribusi normal atau tidaknya sebuah data dalam penelitian. Dalam penelitian ini, uji normalitas yang digunakan adalah uji chi kuadrat. Adapun kriteria penerimaan bahwah suatu data pretest dan posttest hasil tes vertical jump peserta ekstrakurikuler berdistribusi normal atau tidak, yaitu
$\mathrm{X}^{2}$ hitung $<\mathrm{X}^{2}$ tabel, maka data berdistribusi normal atau jika $X^{2}$ hitung $>X^{2}$ tabel, maka data tidak bertribusi normal. Pengujian normalitas dalam penelitian ini dilakukan dengan bantuan aplikasi Microsoft Excel 2010. Hasil pengujian normalitas data prestes dan posttst hasil tes vertical jump peserta ekstrakurikuler dapat dilihat pada tabel di bawah ini.

Hasil Uji Normalitas Data Hasil Pretest dan Posttest Hasil tes vertical jump

\begin{tabular}{|c|c|c|}
\hline Statistik & Pretest & Posttest \\
\hline $\mathrm{N}$ & 20 & 20 \\
\hline$\overline{\mathrm{X}}$ & 48,6 & 58,1 \\
\hline $\mathrm{SD}$ & 7,36 & 6,73 \\
\hline$\chi^{2}$ hitung & 4,958 & 7,62 \\
\hline$\chi^{2}$ tabel & 9,488 & 9,488 \\
\hline Kesimpulan & Data berdistribusi normal & Data berdistribusi normal \\
\hline
\end{tabular}

untuk data hasil pretest diperoleh $\chi^{2}$ hitung $<\chi_{\text {tabel }}^{2}(4,958<9,488)$, sedangkan data hasil posttest diperoleh $\chi^{2}$ hitung $<\chi^{2}$ tabel $(7,62<$ 9,488). Dengan demikian, dapat disimpulkan bahwa data hasil pretest dan posttest hasil tes vertical jump berdistribusi normal.
Pengujian homogenitas varians digunakan uji $F$. Adapun hasil uji homogenitas yang telah dilakuakan dapat di lihat tabel $4.4 \mathrm{~s}$ ebagai berikut: 
Hasil Uji Homogenitas Data Hasil Pretest dan Posttest Hasil

\begin{tabular}{|c|c|c|}
\hline Statistik & Pretest & Posttest \\
\hline $\mathrm{S}^{2}$ & 7,74 & 17,63 \\
\hline $\mathrm{F}_{\text {hitung }}$ & \multicolumn{2}{|c|}{2,28} \\
\hline $\mathrm{F}_{\text {tabel }}$ & \multicolumn{2}{|c|}{4,38} \\
\hline Kesimpulan & Data homogen \\
\hline
\end{tabular}

hasil perhitungan uji homogenitas data hasil pretest dan posttest diperoleh Fhitung $=2,87$, sedangkan Ftabel $=4,38$. Dari hasil perhitungan uji homogenitas tersebut didapatkan Fhitung < Ftabel, maka dapat disimpulkan bahwa data hasil pretest dan posttest hasil tes vertical jump peserta ekstrakurikuler mempunyai varians yang sama atau homogen.

Analisi data dilakukan dengan uji-t pada data pretest dan posttes pengukuran hasil tes vertical jump pada peserta ekstrakurikuler SMK Negeri 1 Kayong Utara yang telah diuji normalitas dan uji homogenitas. Pada tahap ini akan menguji hipotesis terhadap pengaruh metode plyometrix terhadap kemampuan vertical jump pada peseta ekstrakurikuler SMK Negeri 1 Kayong Utara.

Pada uji-t diperoleh nilai $\mathrm{t}$ hitung, sebesar 6,955 dan nilai t tabel pada db ( $0,05 x$ 19) sebesar 2,093. Oleh karena nilai t hitung lebih besar dari $t$ tabel (5,762>2,093), ini artinya Ha diterima , Ho ditolak maka dapat disimpulkan bahwa terdapat pengaruh metode plyometric terhadap kemampuan vertical jump pada siswa ekstrakurikuler SMK Negeri 1 Kayong Utara.

Rangkuman Hasil Uji-t

\begin{tabular}{|c|c|c|c|}
\hline Data & Db & Nilai t hitung & Nilai t table \\
\cline { 1 - 4 } Pretest & \multirow{2}{*}{19} & 6,955 & 2,093 \\
\cline { 1 - 3 } Posttest & \multicolumn{3}{|c|}{ Terdapat Pengaruh } \\
\hline Keputusan
\end{tabular}


Berdasarkan tabel diatas dapat diketahui bahwa nilai rata-rata untuk data pretest adalah sebesar 48,6 dan nilai rata-rata untuk data posttest sebesar 58,1. Hasil ini menunjukan hasil tes vertical jump peserta peserta ekstrakurikuler SMK Negeri 1 Kayong Utara setelah diberikan perlakuan menggunakan motode plyometric meningkat sebesar 9,5 atau sebesar 19,5\% dari saat pretest. Menghitung persentase peningkatan dilakukan dengan cara selisih nilai rata-rata pretest-posttes dibagi nilai rata-rata pretest dikali $100 \%$, Dalam hal ini dapat dikatakan pengaruh yang diberikan menggunakan motode plyometric sebesar 19,5\%. Perhitungan secara lengkap dapat dilihat pada lampiran skripsi ( lampiran 15 halaman 97).

\section{Pemahasan}

Penelitian ini dilakukan untuk membuktikan hipotesis yang menyebutkan bahwa terdapat pengaruh metode plyometric terhadap kemampuan vertical jump pada siswa ekstrakurikuler SMK Negeri 1 Kayong Utara. Hasil penelitian menujukan bahwa terdapat pengaruh yang signifikan dari metode plyometric terhadap kemampuan vertical jump pada siswa ekstrakurikuler SMK Negeri 1 Kayong Utara. Meskipun demikian, masih ditemukan ada tujuh pesrta ekstrakurikuler pada saat posttest memperoleh lompatan yang kurang maksimal. Hal ini disebabkan pada saat mengikuti program latihan plyometric box peserta ekstrakurikuler kurang focus atau tidak serius dalam menerima materi latihan plyometric box.

Analisi uji-t menujukan bahwa thitung lebih besar dari t tabel $(6,955>2,093)$, hal ini mengindikasikan bahwa terdapat perbedaan yang signifikan antara pretest dan posttest, sehingga hal ini menunjukan bahwa terdapat pengaruh yang signifikan metode plyometric box terhadap kemampuan vertical jump pada siswa ekstrakurikuler bola voli di SMK Negeri 1 Kayong Utara. Pada saat pretest besarnya nilai rata-rata adalah sebesar 48,6 dan nilai rata-rata untuk data posttest adalah sebesar 58,1. Hasil ini menunjukan hasil tes vertical jump pada peserta ekstrakurikuler SMK Negeri 1 Kayong Utara setelah diberikan perlakuan menggunakan metode plyometric meningkat sebesar 9,5 atau sebesar 19,5\% dari saat pretest. Dalam hal ini dapat dikatakan pengaruh yang diberikan menggunakan metode plyometric sebesar 19,5\%. Pencapaian ini sesuai dengan penelitian yang dilakukan Edwan (2017) yang menyatakan bahwa persentase latihan plyometric berpengaruh terhadap jumping smash yaitu sebesar $17,13 \%$.

Hasil penelitian ini memberikan suatu gambaran yang jelas bahwah keberhasilan latihan terkait pada beberapa faktor. Faktorfaktor tersebut berasal dari pelatih maupun peserta ekstrakurikuler serta alat/media yang digunakan. Dwiyogo (2009) yang menyatakan pelatih yang baik adalah orang yang imajinatif dalam melaksanakan program olahraga dengan berlandaskan pada ilmu. Sedangkan faktor dari peserta ekstrakurikuler yaitu minat dan motivasi peserta ekstrakurikuler dalam menggikuti proses latihan. Faktor dari peserta ekstrakurikuler ini dikuatkan oleh pernyataan Putra (2015) bahwa penguasaan teknik dasar permaianan bola voli harus benar-benar dilakukan, sebab penguasaan teknik dasar bola voli merupakan salah satu unsur yang turut menentukan menang kalahnya suatu regu dalam pertandingan, disampig kondisi fisik taktik dan mental. Ketersedian alat/media latihan yang menarik dapat juga membantu motivasi atlit sehingga akan diperoleh hasil latihan yang optimal.

latihan melalui penerapan metode plyometric memberikan motivasi dan semangat baru pada atlit bola voli, hal ini dapat diamati dari sikap peserta ekstrakurikuler yang semangat dan percaya diri pada saat melakukan penilaian tes vertical jump. 


\section{Simpulan dan Saran}

Berdasarkan hasil analisis data, pengujian hipotesis dan pembahasan yang telah dikemukan dapat disimpulkan bahwa terdapat pengaruh yang signifikan metode plyometric terhadap hasil tes vertical jump pada peserta ekstrakurikuler SMK Negeri 1 Kayong Utara. Hasil analisis uji-t menunjukan bahwa nilai thitung 6,955 dan ttabel 2,093 atau $(6,955>2,093)$. Besarnya persentase pengaruh yang diberikan latihan menggunakan metode plyometric terhadap hasil tes vertical jump peserta ekstrakurikuler SMK Negeri 1 Kayong Utara adalah 19,5\%.

Berdasarkan hasil penelitian yang dilakukan, saran yang dapat diberikan adalah sebagai berikut :

1. Peserta ekstrakurikuler diharapkan untuk meningkatkan hasil latihan tidak hanya pada cabang bola voli saja tetapi metode plyometric juga dapat diterapkan pada cabang olahraga lainnya.

2. Hendaknya setiap pelatih lebih inovatif untuk membuat dan menerapkan metodemetode latihan yang baru agar dapat meningkatkan hasil latihan vertical jump pada peserta ekstrakurikuler.

\section{DAFTAR RUJUKAN}

Arizal, Y., \& Lesmana, H. S. (2019). Pengaruh Latihan Plyometric terhadap Kemampuan Smash Bolavoli.

Bagaskara (2018). Pengaruh Latihan Plyometric Box Jump Dan Plyometric Standing Jump Terhadap Kemampuan Vertical Jump Pada Atlet Klub Bola Voli Putra Ganevo Usia 14-17 Tahun. Skripsi. Universitas Negri Yogyakarta.

Damanik, S. A. (2014). Pramuka Ekstrakulikuler Wajib Di Sekolah. Jurnal Ilmu Keolahragaan. 13(2). 1621.

Dwiyogo. (2009). Olaharaga dan Pembangunan. Malang: Wineka Media
Indri dan Juliaster. (2009). Tipe dan Trik Membimbing Olimpiade dan Riset Untuk tingkat SMA dan Perguruan Tinggi. : Guepedia

Listina, Ria. (2012). Mengenal Olahraga Bola Voli. Jakatra Timur: PT Balai Pustaka.

Lubis, J. (2009). Mengenal latihan pliometrik. (Online) http://google.com/archive/Mengenal Latihan Pliometrik.pdf. Di akses tanggal 08/01/20Maksum, A. (2007) Statistik Dalam Olahraga. Surabaya: FIK UNESA

Nafi'ah, Z., \& Suyanto, T. (2014). Hubungan Keaktifan Siswa Dalam Ekstrakurikuler Akademik Dan Non Akademik Terhadap Prestasi Belajar Siswa Kelas Viii Smp Negeri 1 Mojokerto. Kajian Moral dan Kewarganegaraan. 3(2). 799-813.

Pertiwi, D.E. (2016) Pengaruh Latihan Dupth Jump Knee Tuck Jump dan Putra Mustika Blora. Semarang : Universitas Negeri Semarang

Putra, A.P. (2015). Peningkatan Kemampuan Akurasi Bola Voli Dengan Metode Target Game Peserta Didik Kelas VII SMP Negeri 4 Kalasan Sleman. Yogyakarta: Universitas Negeri Yogyakarta

Prasetyo, B \& Jannah, M. L. (2012). Metode Penelitian Kuantitatif Cetakan ke 7. Jakarta: PT Raja Grafindo.

Setyawan, A. (2015). Hubungan Antara Tinggi Badan, Power Otot Lengan Dan Power Otot Tungkai Terhadap Ketepatan Smash Bola Voli. Skripsi. Universitas Nusantara PGRI UNP Kediri.

Sugiyono. (2009). Metode Penelitian Kuantitatif, Kualitatif dan R\&D. Bandung: ALFABETA

Sugiyono. (2017). Statisik untuk Penelitian. Bandung: ALFABETA

Zubaedi. (2013). Desinge Pendidikan Karakter Konsep dan Aplikasinya dalam Lembaga Pendidikan. Jakarta: Kenacana 